\title{
AMÉRICA LATINA NO SISTEMA-MUNDO: questionamentos e alianças centro-periferia
}

\author{
Jaime Preciado*
}

\begin{abstract}
A matriz econômica e política latinoamericana e caribenha, está dividida internamente pela emergência de blocos supranacionais que cobram nova projeção geopolítica, mediante negociações entre espaços e âmbitos do poder centro-periferia. Implementam-se, a partir daí, estratégias que influem na nova configuração do sistema-mundo. Neste artigo, identificam-se os Estados-nação com capacidade de projetar-se como uma semi-periferia ativa. O México tem por objetivo reforçar a estratégia da América do Norte e coloca-se como semiperiferia subalterna. O Brasil projeta-se como uma semiperiferia com aspirações de potência global Sul-Norte, que questiona e redefine sua relação com os poderes centrais mundiais. A emergência de uma semiperiferia anti-hegemônica é comandada pela Venezuela, mediante uma ativa política internacional Sul-Sul. Simultaneamente, emergem novos atores alter-mundistas que não se limitam ao mapa de governos nacionais de "esquerda", mas portam um imaginário social alternativo e anti-hegemônica do Sistema-Mundo.

PALAVRAS-CHAVE: geopolítica, relações internacionais, América Latina e Caribe, sistema-mundo, atores altermundistas.
\end{abstract}

\section{INTRODUÇÃO}

A matriz econômica e política latino-americana e caribenha encontra-se dividida internamente pela emergência de blocos supranacionais que cobram uma nova projeção geopolítica, a qual não se limita à dimensão econômica e comercial, mas abrange também negociações crescentes de espaços e âmbitos de poder entre o centro e a periferia. São negociações que implicam posições divergentes. Por um lado, há as alianças mais ou menos incondicionais entre o Norte e o Sul - cuja mostra mais evidente é representada pelo espaço norteamericano do Tratado de Livre Comércio da América do Norte (TLCAN), da Aliança para a Segurança e Prosperidade da América do Norte (ASPAN) e pela disputa pelo espaço meso-americano com o Plano Puebla Panamá+Colombia

* Professor e Pesquisador do Departamento de Estudos Ibéricos e Latino-americanos, da Universidade de Guadalajara (México)

Guanajuato 1045, Zona Centro. Guadalajara, Jalisco. Cep: 44630 Mexico.japreco@megared.com.mx;japreco@hotmail.com $\mathrm{O}$ autor agradece a colaboração de Pablo Uc, Licenciado em Estudos Internacionais.
$(\mathrm{PPP}+\mathrm{C})$ e Tratado de Livre Comércio entre República Dominicana, América Central e Estados Unidos da América (DR-CAFTA:Dominican RepublicCentral America Free Trade Agreement), além do próprio Plano Colômbia. Por outro lado, questionam-se os poderes centrais mundiais, a partir de novas configurações e alianças de Sul a Sul - cuja versão mais visível é a União de Nações Sul-Americanas (UNASUL), seu novo sistema bancário e as novas alianças energéticas e de infra-estrutura na Iniciativa para Integração da Infra-Estrutura Regional Sulamericana (IIRSA), o Mercado Comum do Sul (MERCOSUL) e as propostas da Alternativa Bolivariana das Américas (ALBA).

Essa dimensão supranacional conduz a um reagrupamento ou uma reorganização das relações internacionais, que configura os blocos do poder central em direção à periferia, e dela emergem estratégias que influem na nova configuração do sistema-mundo. Nesse contexto, os intermediários ou os mediadores que encontramos na América Latina e no Caribe são os Estados nacionais com capacidade para projetar-se como uma semiperiferia ativa: Brasil e México. O primeiro, a partir do 
questionamento dos poderes centrais mundiais, com o projeto de constituir-se numa potência global (já reconhecida como tal pela União Européia, em 2007), enquanto o México se projeta como parte do fortalecimento estratégico da América do Norte, embora numa posição subordinada ao centro, os Estados Unidos.

A emergência dessa semiperiferia latinoamericana produz, por sua vez, um realinhamento do mapa de alianças e rivalidades entre os Estados nacionais que gravitam em sua volta. O conjunto de Estados nacionais não está isento da influência de novos atores nacionais e supranacionais de caráter anti-neoliberal, cujas resistências condicionam as projeções geopolíticas de regiões subnacionais, países e blocos supranacionais - com uma força que não se limita ao novo mapa de governos nacionais de esquerda-, ao mesmo tempo em que tais atores são portadores de outro imaginário social do sistema-mundo, que se necessita indagar se é alternativo.

\section{DELINEAMENTOTEÓRICO}

Dentro dos enfoques mais citados no surgimento da geopolítica crítica, encontram-se as análises dos sistemas mundiais. Um dos autores mais destacados nessa proposta é Peter Taylor, que considera a possibilidade de se analisar a escala global a partir de uma perspectiva crítica, separada da escola realista da geopolítica, a qual assume as condições imperantes da geografia política mundial como dadas, naturalizando o status quo.

O objetivo de Taylor foi estudar a configuração histórico-espacial da mudança social, tal e como foi proposto por Immanuel Wallerstein, mas agregando a perspectiva histórica da longue durée e a crítica neomarxista das teorias do desenvolvimento, nas quais fundamenta sua análise de sistemas históricos e sua matriz espacial.

A geografia política que Taylor desenvolve retoma, como base de identificação espacial, as estruturas tripartites da economia-mundo - centros, periferias e semiperiferias - que são entendi- das por Wallerstein como processos de exploração da economia-mundo, e também implicam uma representação espacial do mundo ligada às mudanças de ritmo dos ciclos de auge e crises dos que estão submetidos à economia capitalista. Além do mais, distingue outras três escalas de análise, ligadas a dimensões específicas: a economia-mundo, vinculada à realidade; a localidade, vinculada à experiência; e o Estado-nação, relacionado ao âmbito da ideologia (Taylor; Flint, 2002, p. 35).

Esse enfoque, não obstante, ao conceber a economia-mundo como escala decisiva, não dá conta das atuais contradições que o sistema mundial atravessa. A escala exclusiva do Estado-Nação não é suficiente para explicar os atuais processos mundiais, e é inegável a persistente presença de um esquema estado-cêntrico, sem o qual a economia política capitalista e os predominantes discursos sobre globalização não poderiam sustentar-se.

Como já se afirmou, a matriz econômica e política latino-americana e caribenha está dividida internamente pela emergência de blocos supranacionais que cobram uma nova projeção geopolítica, a qual não se limita à dimensão econômica e comercial, mas abrange uma negociação crescente de espaços e âmbitos de poder entre o centro e a periferia. Por outro lado, o surgimento de redes transnacionais da sociedade civil persiste, com reivindicações comuns e plurais, apontando para uma transformação social, com o que obtêm também sua própria identidade espacial e um constante processo de territorialização da resistência aos processos antes exclusivos da economia mundial e do Estado.

Dessa forma, existe uma sobreposição de escalas espaciais que atuam de maneira paralela, dando uma particular complexidade à configuração da América Latina e Caribe no sistema-mundo contemporâneo.É fundamental considerar ou acionar tais escalas, que ultrapassam a especialização tripartite tradicional, para compreender a atual situação e a emergência de semiperiferias na América Latina, assim como o imaginário social alternativo em luta contra os processos, escalas e dimensões políticas, econômicas e culturais dominantes. 
Nos processos de centro e periferia, há um papel determinante da semiperiferia. $\mathrm{O}$ uso dos termos centro e periferia, na análise dos sistemasmundo, não se refere, em primeira instância, a zonas geográficas, regiões ou Estados, mas a processos complexos. Essas zonas se convertem em centrais, porque dominam os processos de exploração e concentração de mais valia, e, da mesma forma, as regiões periféricas são definidas por sua condição de exploradas pelo centro e subordinadas a seus processos centralizadores e concentradores de recursos.

Os processos de centro consistem em relações que combinam salários relativamente altos, tecnologia moderna e um tipo de produção diversificada. Os processos da periferia constituem uma combinação de baixos salários, tecnologia mais rudimentar, resultando num tipo de produção simples.

A semiperiferia é o espaço que combina, de uma forma particular, ambos os processos. Esse conceito se aplica diretamente a zonas, regiões ou Estados que supõem a exploração da periferia e sofrem a exploração do centro. Essa categoria é a que contém maior dinamismo, e exige a incorporação de processos e perspectivas políticas, a par da análise econômica.

\section{ALIANÇAS DAS SEMIPERIFERIAS COM OS BLOCOSECONÔMICOS E EXTRA-ECONÔMI- COS CONTINENTAIS}

O conjunto das alianças e blocos supranacionais que configura as diferentes opiniões econômicas, políticas e militares do hemisfério ocidental compreende o estado atual das relações entre centro e periferia na América Latina. Por um lado, é possível identificar as relações, mais ou menos incondicionais e persistentes nos últimos anos, entre o Norte e o Sul, sob um cenário de contínuas iniciativas que ressaltam a liderança e a dominação estadunidense, aliança na qual o México apostou. Por outro lado, são identificadas as alianças e blocos Sul-Sul, que questionam, em distinto grau, a estrutura dos poderes centrais no sistema-mundo e o esquema dominante no continente. As iniciativas Sul-Sul são comandadas pelo Brasil, e sua estratégia é conformar-se como potência global autônoma, sem orientação necessariamente dos Estados Unidos, enquanto que a Venezuela se configura como semiperiferia emergente, o que supõe resistências anti-hegemônicas frente aos Estados Unidos.

O esquema de relações Norte-Sul se forma em torno de um eixo econômico-comercial e outro político-militar. No primeiro caso, México delineia seu contexto de semiperiferia subordinada, ao incorporar-se ao persistente TLCAN, primeiro projeto de integração assimétrica Norte-Sul no continente, entre Estados Unidos, Canadá e México. Por outra parte, encontra-se o projeto de integração comercial continental, estimulado pelos Estados Unidos, a Área de Livre Comércio das Américas (ALCA), que, depois da Cúpula Ministerial de Miami, em 2003, foi reprojetada como uma ALCA de dois níveis: um primeiro, constituído por um acordo guarda-chuva ou de base, capaz de definir direitos e obrigações para todos os países signatários, e um segundo nível, constituído por acordos bilaterais e multi-bilaterais entre países dispostos a tomar mais compromissos que os estabelecidos no acordo-base.

Esse último nível é o dominante, tal como demonstra a vigência do Tratado de Livre Comércio (TLC), entre Estados Unidos e Chile; do TLC entre Estados Unidos, América Central e República Dominicana (CAFTA+DR, sigla em inglês); do TLC entre Estados Unidos e Panamá. Há também negociações em processo de TLCs com Colômbia e Peru, e projetos de integração subordinada Norte-Sul, com os quais o México se compromete ativamente, mesmo depois do fracasso da IV Cúpula das Américas em Mar del Plata (Argentina), em 2005.

Os Estados Unidos, principal sócio comercial da contraparte, cria canais de controle que outorgam a Washington poder sobre os termos de negociação, com capacidade para limitar as estratégias de diversificação que os Estados latino-ame- 
ricanos requerem. Com isso, dispõem de uma ferramenta permutável para a obtenção de concessões estratégicas, tal como ocorre com a Colômbia ou o Paraguai, que concederam parâmetros de imunidade militar aos Estados Unidos e até concessões para a instalação de bases militares, no primeiro caso.

Esse último fato leva ao marco do eixo político-militar, em que se destaca, seguindo uma orientação Norte-Sul, o acordo ea implementação da ASPAN, caracterizada pela sua baixa institucionalidade parlamentar, pela ausência de uma agenda social e de legitimidade política para a aprovação de faculdades extraordinárias aos grupos empresariais privados com maior poder comercial e político, nas economias do Canadá, Estados Unidos e México, e a implementação de uma ampla agenda de segurança sanitária, alimentação, energia e militar (Preciado, 2008). Trata-se de uma estratégia que combina segurança e negócios, promovida com entusiasmo pelos governos mexicanos de Vicente Fox (2000-2006) e de Felipe Calderón (2006-2012), como um dos pilares geoestratégicos que constituem o México como semiperiferia subordinada.

A ASPAN se insere no contexto de políticas de segurança preventiva e da denominada Guerra Global contra o Terror (GWOT, sigla em inglês) inerente à doutrina de segurança estadunidense, aplicada à região após o 11 de Setembro, na qual se destaca a Área de Responsabilidade do Comando Norte (AOR), criada em outubro de 2002, que compreende desde o Alasca até a fronteira sul mexicana, incluindo parte do Caribe, e 500 milhas náuticas tanto do Pacifico como do Atlântico. O Comando Norte, projeta a mais contundente extensão do perímetro de segurança regional norte-americano.

Seguindo até o Sul, na região mesoamericana que abarca o Sudeste do México e a América Central, encontra-se o Plano Puebla Panamá, reativado em outubro de 2006, depois da adesão da Colômbia (PPP+Colômbia). Com ele, a potência do Norte projeta seu funcionamento como ferramenta geopolítica de vinculação Sul-Sudeste, na qual o México representa a conexão entre a América Cen- tral e os Estados Unidos, como nexo entre esse último e as duas estratégias de segurança ativa no coração da região andina: o Plano Colômbia e a Iniciativa Regional Andina. O primeiro continua representando o pacote de assistência militar estadunidense mais importante na América Latina, que não somente reativou uma segunda fase na luta contra o narcotráfico, em 2002, mas também uma ofensiva militar contra-insurgente denominada Plano Patriota, nos territórios controlados pela guerrilha no sul da Colômbia.

Além da aproximação diplomática entre México e Colômbia em foros e instâncias internacionais, há que acrescentar a Iniciativa Mérida, também conhecida como Plano México, que está pensada como uma adaptação mexicana do Plano Colômbia, a partir do Departamento de Estado norteamericano. Seu financiamiento seria bilateral, ainda que o Congresso dos Estados Unidos pedisse garantias prévias de sua aprovação ao governo mexicano, relativas ao respeito de direitos humanos no combate ao narcotráfico, apesar da aprovação unilateral de um fundo extraordinário de 500 milhões de dólares por parte do Presidente Felipe Calderón.

Por sua vez, a política exterior do México procurou aproximar-se da Iniciativa Andina, a qual representa a extensão regional dos objetivos primários do Plano Colômbia, sob uma lógica de contenção contra o narcotráfico nos países vizinhos, perante o efeito rebote gerado pela luta de erradicação anti-droga. Não obstante, a regionalização do projeto inclui a implementação de programas de crescimento econômico, mediante o apoio às políticas baseadas no mercado, incluída a negociação da ALCA e a implantação da Lei de Preferência Comercial Andina (LPCA).

A esses projetos bilaterais e regionais de assistência é importante agregar a negociação de alianças e concessões militares feitas por alguns países do Cone Sul aos Estados Unidos, já que representam parte estrutural das relações entre o centro norte-americano e a periferia e semiperiferia latino-americana. Após a retirada do Canal do Panamá, em 1999, os Estados Unidos obtiveram uma 
ampliação de sua área de ação a partir de três novas posições estratégicas na região andino-amazônica, por um período de dez anos, formando um triângulo estratégico em torno do Panamá, da Colômbia e da Venezuela. ${ }^{1}$

No tocante às alianças e blocos Sul-Sul, é possível identificar, por um lado, um eixo de integração econômico-comercial, com uma agenda política e social cada vez mais ampla, que perdura, ao menos, desde a década passada. Por outro lado, existem as alianças e projetos de integração mais recentes e inovadores, caracterizados pelo espírito enfático latino-americanista, que domina de maneira relativamente uniforme, ainda que com matizes diferenciados, o discurso dos governos de esquerda e de centro-esquerda na região.

No primeiro eixo, encontra-se o Mercosul, que continua fortalecendo sua institucionalização com uma destacada liderança do Brasil, no qual a Venezuela se encontra em processo de incorporação como membro pleno, desde que o congresso brasileiro assim o aprove. Enquanto isso, Bolívia, Peru, Chile, Colômbia eEquador permanecem como estados associados, mediante Acordos de Complementação Econômica (ACE), que estabelecem um cronograma para a criação de áreas de livre comércio entre cada um desses países e a região do Mercosul. Esse processo de aprofundamento SulSul, do Mercosul, constitui o esforço para gerar convergências entre sua agenda e a da Comunidade Andina de Nações (CAN). ${ }^{2}$

Seguindo no mesmo eixo, existem dois elementos-chave, nos anos mais recentes, relacionados com a CAN. O primeiro representa a saída da Venezuela da Comunidade Andina, em abril de

${ }^{1}$ A primeira no aeroporto internacional de Comalapa, em El Salvador; nos aeroportos de Reina Beatriz e Hato Rey, nas ilhas de Aruba e Curaçao ao norte de Venezuela, respectivamente; e no aeroporto Eloy Alfaro, na cidade de Manta, Equador. Esses novos centros operativos, primeiramente denominados Foreign Operating Locations (FOL), e posteriormente Cooperative Security Locations (CSLs), caracterizam-se por um sistema de comunicação em tempo real e uma envergadura que muda de acordo com uma lógica de mercado just in time, eficiente de acordo às necessidades que se apresentem (Ceceña, 2008).

2 Destaca-se, nesse processo, a assinatura de um TLC com Israel, em finais de 2007, como sua primeira iniciativa extracontinental.
2006, apoiada no argumento exposto pelo presidente Hugo Chávez, que considera os TLCs firmados pela Colômbia e pelo Peru com os Estados Unidos como geradores de prejuízos imediatos à normativa e princípios básicos da CAN, tornando-a um mecanismo inservível. O segundo é a incorporação do Chile como membro associado, depois de sua retirada do então Pacto Andino, durante a ditadura de Augusto Pinochet. Ainda que esse último fator represente um potencial alívio para a Comunidade Andina, dado o volume comercial que representa a economia chilena, a retirada da Venezuela foi parte de uma relativa, ainda que não transcendente, convulsão do cenário de integração regional da América do Sul.

Essa integração Sul-Sul tem seus conflitos. Por exemplo, as relações internas do Mercosul foram abaladas pelas críticas do Uruguai e do Paraguai ao Brasil e à Argentina, perante o que denominaram atitudes discriminatórias e assimétricas no mecanismo de integração. Por um lado, as relações bilaterais entre Argentina e Uruguai se viram desgastadas pela construção de fábricas de celulose em Fray Bentos, e pelo aprofundamento das relações entre Uruguai e Estados Unidos. Por outro lado, a nacionalização do gás na Bolívia gerou tensões desse país com o Brasil, dado o efeito negativo aos interesses dos acionistas da Petrobras, e com a Argentina, diante da alta anunciada nos preços do gás natural, o que representa altos custos, devido à sua dependência crescente de importação desse produto.

Além dessas duas grandes instituições regionais que aglutinam os países de maior importância do Cone Sul, é importante assinalar a continuidade nos processos da Comunidade do Caribe (CARICOM) e da Associação de Estados do Caribe (AEC) instância onde o México perdeu sua liderança, a qual manteve sua institucionalização para a integração na região do Caribe, a partir de um enfoque predominante Sul-Sul, ainda que não único.

Nas alianças mais recentes, destacam-se: a UNASUL, criada em 2004, na III Cúpula SulAmericana, que está concentrada na coordenação 
política e diplomática da região; a convergência das agendas do Mercosul, da CAN e o Chile; a integração física, energética e de comunicações na América do Sul, mediante o impulso à IIRSA: e um conjunto de projetos com relativa autonomia. No eixo econômico-financeiro, destaca-se a criação do Banco do Sul, em finais de 2007, orientado para fornecer apoio à criação de infra-estrutura e apoio empresarial público e privado na região.

Essa iniciativa - promovida pela Venezuela e apoiada, até agora, pelos membros do Mercosul, Bolívia e Equador - representa uma enfática alternativa ao Fundo Monetário Internacional, ao Banco Mundial e ao Banco Interamericano de Desenvolvimento, ou seja, a todo um esquema financeiro que dirige a transferência de recursos econômicos dos processos de centro à periferia, condicionados a modelos de desenvolvimento que promovam uma baixa atividade estatal no comércio e à abertura dos mercados nacionais. Entre as medidas previstas pelo Banco do Sul que mais se destacam, encontra-se a disposição para que cada país tenha direito a um voto igual, sem importar o tamanho de suas contribuições, na busca de uma real e simbólica ruptura com as assimetrias entre os países latino-americanos.

No plano estratégico-militar, destaca-se a iniciativa para a criação do Conselho Sul-Americano de Defesa, que é liderado pelo Brasil e promovido, constantemente, como uma inevitável necessidade, no discurso venezuelano, relativa à integração. Essa proposta foi aprovada por dez dos onze presidentes e pelo vice-presidente uruguaio, presentes na Cúpula da UNASUL do dia 23 de maio de 2008, para a qual foi criado um grupo de trabalho que, durante noventa dias, irá estudar a forma e organização que terá esse Conselho. Tratase de uma proposta que difere de uma aliança militar tradicional, tal como a Organização do Tratado Atlântico Norte (OTAN), que, de acordo com o ministro de defesa brasileiro, Nelson Jobim, longe de funcionar como uma força operativa, "servirá como organismo consultivo, destinado a assegurar a estabilidade e a paz na região.” (Ramos, 2008) Contudo, é inegável que esse Conselho representa um esquema de autonomia militar frente ao modelo pan-americano de defesa na região, impulsionado pelos Estados Unidos, centrado em projetos tais como o Tratado Interamericano de Assistência Recíproca (TIAR), com exercícios conjuntos e exercícios navais, que destaca o relançamento da Quarta Frota para a supervisão dos mares latino-americanos, a partir do mês de julho de 2008, após cinquenta e oito anos de inatividade (Ballester, 2008).

Portanto, a projeção geopolítica da UNASUL é multidimensional, ao abranger a perspectiva econômico-comercial-financeira, político-militar e social, e sul-latino-americanista, ao considerar o Cone Sul como um espaço que comporta a autonomia política e a emergência econômica da América Latina. Nessa nova instituição, o papel do Brasil como semiperiferia com aspirações de potência global é decisivo.

Ao estruturar um eixo político-ideológico, a ALBA, promovida pela Venezuela e Cuba, foi inicialmente identificada como a principal contraposição à ALCA. Não obstante, independentemente da reorientação que a ALCA tomou a partir de 2005, ela se caracterizou por enfatizar a necessidade de reforçar a integração a partir de um enfoque de cooperação e solidariedade política, social e cultural, destacando a luta contra a pobreza, a exclusão social, a discriminação e o analfabetismo, entre outros elementos. Essa iniciativa, que representa a ponta de lança da proposta de integração bolivariana, tal como propõe o governo de Hugo Chávez, em seu Plano Estratégico da União de Povos e Repúblicas, não somente se concentrou na união dos Estados, o que contempla atualmente Venezuela, Cuba, Bolívia, Nicarágua e República Dominicana, mas também na incorporação de movimentos sociais e da Cúpula dos Povos, para a qual existem alianças com grupos locais em vários países latino-americanos que ainda não tomam parte oficial da iniciativa, destacandose os casos do Peru e do Equador (MPPRE, 2007).

Entre as iniciativas da ALBA com maior impacto, destaca-se a criação dos Tratados de Comércio entre os Povos (TCP), que promove a su- 
bordinação do comércio tradicional, centrado no crescimento econômico, ao desenvolvimento e bemestar social, enfatizando a importância de se abaterem os índices de desigualdade social como a mais importante prioridade entre os países que têm relações comerciais. Os TCP procuram preservar e respeitar as formas de organização comercial indígenas na América Latina, favorecendo a diversidade cultural e o comércio justo. Essa iniciativa se enquadra nas denominadas Cúpulas dos Povos da América, que se converteram em aglutinadoras dos foros alternativos que se realizam frente às cúpulas presidenciais na América Latina. Também ressalta a iniciativa da Telesur, um projeto de comunicação televisiva, impulsionador da perspectiva bolivariana de integração, e uma alternativa midiática, frente aos meios trasnacionais dominantes de comunicação e da imprensa. Dessa forma, a ALBA representa um eixo ideológico claramente anti-hegemônico, transversal ao projeto da UNASUL, mas não contraditório, e sim, em grande medida, complementar.

O último, mas não menos importante eixo formula uma proposta de integração energética como pilar estratégico da integração latino-americana. Essa proposta, impulsionada pela Venezuela, é conhecida como Petroamérica, e está constituída por três iniciativas sub-regionais: Petrosur, em que participarão Brasil, Argentina, Uruguai e Paraguai, ou seja, os membros do Mercosul; Petrocaribe, constituída inicialmente por quatorze países - Antigua e Barbuda, Bahamas, Belize, Cuba, Dominica, Granada, Guyana, Jamaica, República Dominicana, San Cristóbal e Nieves, Santa Lucía, San Vicente e as Granadinas, Suriname e Venezuela -, à qual aderiram formalmente, em 2007, o Haití e a Nicaragua; Petroandina, com a participação da Bolívia, do Equador e da Colômbia (Hernández, 2007). A projeção geopolítica da Petroamérica se vale da subregionalização latino-americana e deixa clara a exclusão do México da perspectiva sul-latino-americana, dada a sua profunda relação de dependência energética do norte, através da ASPAN.

O projeto da Petroamérica se sustenta em três condicionantes geopolíticos vigentes.
O primeiro é o modelo de dependência petroleira que os Estados Unidos, os grandes países consumidores de energia e os emergentes promovem por causa do crescente aumento industrial e seu progressivo gasto energético, o qual foi uma das principais causas do substancial aumento nos preços dos hidrocarbonetos, nos últimos cinco anos. O segundo é a regionalização comercial já existente no Cone Sul e na América Central. Ainda que tenha vários graus de institucionalização e sucesso na sua integração, permitiu converter o ramo energético numa atrativa esfera aglutinadora do projeto de integração regional, o que garante, ao mesmo tempo, a segurança energética dos estados. O terceiro condicionante em que se apoia o projeto da Petroamérica é a projeção da disputa geopolítica entre o código norte-americano e o sullatino-americano, em dois espaços estratégicos: a área da América Central e Caribe, onde se confrontam os projetos do $\mathrm{PPP}+\mathrm{C}$ e o $\mathrm{CAFTA}+\mathrm{RD}$ com a proposta da Petrocaribe, e a extensão da ALBA; a área andina, em que confrontam as iniciativas do Plano Colômbia e a Iniciativa Andina, com a proposta de Petroandina, que até agora é a que mais sofre de sedentarismo e baixa institucionalização.

Assim, é possível distinguir os discursos geopolíticos latino-americanistas, que poderiam se caracterizar como sul-americanistas. Um deles é muito mais enfático na sua rejeição ao papel hegemônico estadunidense na região e nas suas diversas estratégias de dominação comercial, política e militar. Seu portavoz é a ALBA, que, por sua vez, deposita sua solidez material na proposta energética da Petroamérica e na criação do Banco do Sul como alternativa financeira para o Sul-Sul. O outro discurso é o que encabeça a UNASUL, uma iniciativa mais integral, que incorpora e se complementa com a anterior, mas que não se vale do enfoque anti-hegemônico, mas da ênfase na autonomia política regional, e a projeção geopolítica da América do Sul, como bloco competitivo no sentido global. A UNASUL conta com a liderança do Brasil, reconhecido de maneira crescente como potência global e que, por sua vez, pretende con- 
verter-se na plataforma desse país rumo a sua projeção mundial. A emergência de uma semiperiferia anti-hegemônica é comandada pela Venezuela, a partir de uma ativa política internacional.

\section{SEMIPERIFERIAS LATINO-AMERICANAS- IDENTIFICAÇÃO ECARACTERIZAÇÃO}

Enquanto os projetos internacionais e supranacionais Norte-Sul e Sul-Sul impulsionam um reagrupamento e uma reorganização das relações internacionais que configuram os blocos do poder central rumo à periferia, tembém emergem propostas estratégicas que, de um ponto de vista das áreas periféricas, influem na nova configuração do sistema-mundo. Nesse caso, os atores que canalizam com mais contundência essas estratégias, na América Latina e no Caribe, são os Estados nacionais com capacidade para se projetarem como semiperiferia ativa.

EsseéocasodoBrasil, apartir doquestionamento aos poderes centrais mundiais com um projeto de constituir-se numa potência global, já reconhecida como tal pela União Européia, enquanto que o México se projeta no contexto do fortalecimento estratégico da América do Norte, ainda que de uma posição subordinada ao centro: os Estados Unidos. Também é importante identificar as aspirações da Venezuela, que se auto-promove (e obtém uma crescente interlocução) como uma semiperiferia emergente, em busca de uma projeção continental. Sua estratégia, caracterizada por seu enfático discurso anti-estadunidense, promove uma série de projetos reivindicativos da integração bolivariana, mediante alianças políticoideológicas regionais com estados e grupos sociais de esquerda, e um sustentável exercício da petropolítica em âmbito mundial.

A emergência dessa semiperiferia latinoamericana, por sua vez, produz um realinhamento do mapa de alianças e rivalidades entre os Estados nacionais que gravitam em sua volta. Por isso, é importante delinear a projeção geopolítica dos três casos mencionados, a fim de identificar sua posição e seu impacto no sistema-mundo. Por um lado, elaborar um balanço de suas características como Estados fortes, a partir da perspectiva da Geografia Política e as análises dos sistemas-mundo. Por outro lado, revisar um conjunto de indicadores de sua política exterior em direção ao continente e para o resto do mundo, com a finalidade de se reconhecer seu desenvolvimento no sistema internacional e o modo como a emergência de blocos regionais se instrumentaliza, por parte das semiperiferias em estudo, para seu reposicionamento no sistema internacional como potências globais. Também nos interessa analisar se tais estratégias são complementares ou competem com, e (ou) de forma contrária, como semiperiferias, e se isso influi na consolidação da América Latina como bloco regional com crescente autonomia política dentro do sistema-mundo.

Essas considerações são funcionais para o caso do México e do Brasil. Enquanto o México procura a persistente obtenção de certas considerações gerais que o identifiquem como um grande poder regional associado ao Norte, o Brasil demarca claramente as características de um poder regional, e procura, com crescente sucesso, seu posicionamento como um superpoder. Esse é o marco diferencial que mais sobressai entre as estratégias dos dois pivôs regionais mais importantes na América Latina, como resultado do atraso em que a política exterior mexicana se viu implicada desde o mandato do presidente Vicente Fox, caracterizada por uma enfática subordinação ao centro estadunidense, em contraste com a ambiciosa política exterior brasileira, que reclama paulatinamente maiores margens de autonomia.

A seguir, serão esboçadas as características específicas desses três atores estatais latino-americanos: México, Brasil e Venezuela. Os dois primeiros foram reconhecidos, ao longo da década passada, como semiperiferias ativas, tanto por seu papel como Estados Âncora, como por suas características internas e seu posicionamento estrutural no sistema-mundo. No terceiro caso, entrevêem-se os traços que potencializam e limitam sua aspiração a constituir-se como semiperiferia emergente. 


\section{México}

Entre o impulso e o condicionamento de sua posição geopolítica na América do Norte, o México enfrenta um paradoxo, pois queria ser o país "dobradiça" por excelência, situado entre o colosso estadunidense e a América Latina, mas também o interlocutor natural entre ambas regiões. No entanto, o México caiu na contradição de conformar-se em ser um país latino-americano que escolheu um projeto estratégico de integração profunda em direção ao Norte. Assim, demonstra sua profunda dependência comercial dos Estados Unidos e das remessas provenientes desse país, que alcançaram 23.9 milhões de dólares, em 2007, a segunda receita mais importante depois da gerada pelo petróleo.

Os indicadores duros de sua economia colocam o México com uma taxa de crescimento média abaixo de países como Argentina, Brasil, Chile ou Venezuela, com uma média de 3.6\% nos últimos três anos. De acordo com o Relatório de Desenvolvimento Humano 2007-2008, o México ocupa o $52^{\circ}$ lugar no ranking mundial, dentro do grupo de alto desevolvimento humano, e possui um índice Gini de 46.1, que reflete uma desigualdade social maior que a da Argentina, do Chile, do Uruguai ou de Cuba, embora menor que a do Brasil, da Venezuela e da Colômbia.

O México é um país-chave na geopolítica petroleira latino-americana, ao produzir 3.7 milhões de barris diários (mbd) de óleo cru, ou seja, 4.8\% da oferta mundial, equivalentes a $34.7 \%$ da produção regional, o que o converte no principal produtor da região, acima da Venezuela. Não obstante, o nível de suas reservas caiu drasticamente de 48.8 mil milhões de barris em 2005 (mmb) a 13.7, em 2005, enquanto que a projeção de exploração da PEMEX, em 2012, é projetada para alcançar somente $4.7 \mathrm{mmb}$, produzindo assim, uma quantia suficiente para tão somente 3.8 anos. Cenário dramático enfrenta o modelo energético impulsionado pela elite política oficial do Partido Ação Nacional no México, tendo em vista a abertura gradual da indústria petroleira ao setor privado, como con- dição para uma maior integração energética para a América do Norte, de acordo com a agenda de segurança energética da ASPAN. No entanto, a oposição legislativa federal da Frente Ampla Progressista e uma crescente oposição da sociedade civil mexicana lançaram uma importante resistência ao projeto.

No mesmo cenário estratégico, o México se destaca, junto ao Brasil e à Argentina, por ter uma central nuclear geradora de energia elétrica, embora, no sudeste do país, no estado de Chiapas, encontrem-se significativas reservas de urânio, ainda inexploradas. Esses dois elementos constituem, ainda, fatores determinantes na Política Internacional.

Quanto à capacidade militar do México, destaca-se um aumento constante no seu orçamento desde o ano de 2003. Segundo os últimos dados oficiais, para 2006 , foram gastos $\$ 6.07$ bilhões de dólares, o equivalente a $0.5 \%$ do PIB, despesa que o coloca no $162^{\circ}$ lugar do ranking mundial, abaixo do Brasil e do Chile, mas acima da Venezuela. No entanto, a despesa com armamento, capacitação e inteligência foi duramente criticada, por sua enfática missão nas tarefas tradicionais das Forças Armadas e na Segurança Pública interna do país, especialmente na luta contra o narcotráfico.

No que diz respeito às relações extra-continentais do México, em direção aos processos e atores centrais do sistema-mundo, sua adesão aos esquemas de desenvolvimento e liberalização impostos pela Organização para a Cooperação e o Desenvolvimento Econômico (OCDE), desde 1994, unida ao modelo de pagamento sustentado da dívida com o FMI, o BID e o BM, fazem com que, de cada peso gerado na economia mexicana, quase 37 centavos sejam destinados ao pagamento da dívida.

Com respeito aos centros mundiais não continentais, as relações do México com a União Européia não resultaram em diversificação comercial. Mesmo depois do Acordo de Cooperação Comercial (ACE), assinado há uma década, em 1997, o país não conseguiu uma associação estratégica global com a UE que lhe pudesse outorgar um futuro status de potência global. 
Em suas relações com o sudeste asiático, o passo mais significativo foi a assinatura do Acordo da Associação Econômica com Japão, em 2004. No entanto, a aproximação com a Associação de Nações do Sudeste Asiático (ASEAN) limitou-se a declarações e projetos sem acordos. Apesar do incremento do intercâmbio comercial com países como a China, o México não tem uma estratégia de diversificação intensiva para essa região.

Da mesma forma, há um grande atraso de participação e liderança da economia mexicana nos projetos de cooperação Sul-Sul, não somente da região latino-americana, mas também em âmbito mundial, como mostra seu baixo perfil na aliança do G33, realizada na Cúpula da Organização Mundial do Comércio (OMC) de Cancún, em 2004, ou sua participação marginal em reuniões com os países do grupo Brasil-Rússia-Índia-China-Suráfrica (BRICS), o que diminui seu papel como semiperiferia latino-americana. A contrapartida a esses vazios, no entanto, foi relativamente compensada por sua participação no chamado G5, junto às economias emergentes como Brasil, Índia, China e África do Sul, nos fóruns do G7/8, desde o ano 2003, até a última reunião em julho de 2008, no Japão. Da mesma forma, o México tornou-se membro não permanente do Conselho de Segurança das Nações Unidas no período de 2002 a 2003, e aspira a repetir o feito no período de 2009 a 2010.

Os indicadores esboçados projetam, com clareza, o perfil do México como semiperiferia subordinada. Um ator influente na América Latina, mas dependente dos processos de centro, dominantes no cenário da economia-mundo e, particularmente, do ator central do continente: os Estados Unidos. Uma semiperiferia com estratégias de diversificação limitadas, sem liderança na sua região de influência tradicional, distante da América Latina e sem projeto de autonomia política no sistema-mundo.

\section{Brasil}

O papel do Brasil como semiperiferia ativa, na América Latina, não somente se consolidou, mas incrementou, além disso, aspirações na procura de seu posicionamento como potência global. A dimensão e a posição geográfica do Brasil o consolidaram como um Estado de grande relevância estratégica, por ter fronteira com todos os países da América do Sul, com exceção do Peru e do Chile, assim como a extensão territorial e a população maior da América Latina, além de um gigantesco litoral no Atlântico, com zonas preferenciais, chaves no comércio e na exploração de recursos off-shore.

Segundo as estimativas da CEPAL (2007), o Brasil teve um desempenho econômico importante, com um crescimento médio de $4 \%$ nos últimos três anos, ocupando um lugar sólido no crescimento sul-americano. No entanto, no Relatório de Desenvolvimento Humano 2007-2008, o Brasil ocupa o $70^{\circ}$ lugar do ranking mundial de desenvolvimento humano, abaixo da Argentina, do Chile e do México, assim como um índice de Gini de 57.0, que o converte no quarto país latino-americano com maior desigualdade social, depois de Bolívia, Guatemala e Paraguai, e o segundo no grupo BRICS, depois da África do Sul.

O grande parte do papel estratégico do Brasil na América Latina se concentra no cenário energético. Sua produção petroleira é muito menor que a do México e a da Venezuela, embora ela tenha aumentado em 100\%, na década de 1995 a 2005. Quanto às reservas brasileiras, o descobrimento de novas jazidas pela empresa Petrobras, em 2007, pode gerar um aumento dessas reservas em $40 \%$ para o ano 2020 , o que levaria a posicionálo no mesmo nível dos países árabes e da Venezuela.

Além diso, o Brasil é o principal produtor e exportador mundial de etanol de cana, com quase 17 bilhões de litros por ano, e pretende liderar um modelo energético alternativo ao petroleiro, tal como enfatizou na reunião do G8, na Alemanha, em 2007. Essa forte produção de etanol, no entan- 
to, faz com que o país enfrente a crescentes críticas por produzir biocombustíveis em vez de alimentos. Na linha da energia nuclear, o Brasil possui a sexta reserva mundial de urânio, apenas explorada em $30 \%$. O governo tem como projeto privatizar a exploração do urânio, com o objetivo de aumentar, em âmbito regional, o uso da energia nuclear para a geração de energia elétrica.

O Brasil, apoiado pela Argentina, cancelou sua dívida com o FMI em 2006, marcando uma pauta simbólica e real de autonomia econômicofinanceira frente ao modelo dominante de desenvolvimento que as instituições financeiras internacionais vinham impondo no marco do Consenso de Washington, desde meados dos anos oitenta na América Latina. Mesmo assim, o FMI e o BM reconheceram o Brasil como terceiro maior credor do grupo de países emergentes, depois da China e do Kuwait.

A participação brasileira é destacada no G4, que inclui Alemanha, Japão e Índia, para reformar o Conselho de Segurança da ONU e estabelecer um número adicional de lugares permanentes, na sua carreira para obter um deles. A diplomacia brasileira participou nas cúpulas ministeriais do G8, em 2006, como país não membro, promovendo, ademais, a cooperação Sul-Sul na conformação do grupo BRIC, com Rússia, Índia, China e, posteriormente, África do Sul, o que significou a ampliação do triângulo Moscou-Nova Delhi-Pequim, em direção à América Latina. Isso faz com que o país se consolide como o principal interlocutor sul-americano com projeção geopolítica e capacidade de gestão global.

A liderança brasileira se expressa no G20, no marco da rodada de Doha, junto com o lançamento da iniciativa Ação contra a Fome e a Pobre$z a$, com os presidentes da França e do Chile, com o objetivo de gerar uma alternativa para o financiamento dos instrumentos para o desenvolvimento. No entanto, essa liderança é questionada pela esquerda, por aceitar o mandato sobre a Missão de Mantenutenção da Paz em Haiti (MINUSTAH) desde 2004, contribuindo com o maior contingente dessa missão.
O último indicador de ampla relevância foi o reconhecimentocomo potência global, concedido pela União Européia na Cúpula de Lisboa, em 2007, uma classificação que, até a presente data, só havia sido concedida a Estados Unidos, Canadá, Rússia, China, Índia e Japão. Essa ação abre uma lacuna no equilíbrio regional latino-americano, que mantinha o México e o Brasil no mesmo nível.

\section{Venezuela}

O papel da Venezuela, no cone sul-americano, possui uma dupla condição paradoxal, de liderança regional, dada sua capacidade de influenciar e encabeçar iniciativas conjuntas de integração regional, especificamente no campo energético, e de um eixo ideológico, com um discurso antihegemônico, que questiona os fundamentos básicos de exploração das periferias no sistema-mundo, assim como a dependência dos centros mundiais. Contudo, esse mesmo impulso de liderança ideológica, agregado ao protagonismo do presidente Hugo Chávez, gerou uma negativa agenda de conflitos diplomáticos, distanciamentos políticos e tensões geopolíticas com seus vizinhos latino-americanos. Um desses casos é a significativa tensão em sua fronteira com a Colômbia, o mais importante enclave estratégico dos Estados Unidos na região.

A fortaleza do Estado venezuelano se expressa por um crescimento do PIB superior a 8.5\% , em 2007, um dos mais altos na América Latina, em grande medida promovido pela alta nos preços do petróleo. Enquanto isso, seu IDH o posiciona ainda dentro do grupo de países de desenvolvimento humano mediano, no $74^{\circ}$ lugar do ranking mundial, e com um índice de Gini de 48.2, que o coloca em posição de menor desigualdade no nível de renda em comparação com o Brasil, México, Colômbia e Chile.

Entretanto, o gasto militar da Venezuela alcançou quatro bilhões de dólares em 2007, segundo o Balanço de Política Estratégica de Defesa e Assuntos Exteriores do Sistema de Informação Glo- 
bal, 2006/2007, o que significou um aumento de $12.6 \%$ com relação a 2005. A assinatura de acordo com a Rússia para a compra de armas, assim como a possível instalação da primeira fábrica de rifles Kalashnikov na América Latina, tem fundamentalmente um caráter estratégico frente aos Estados Unidos, que lhe proibiram a venda de armas e foram acusados de representar uma ameaça potencial à soberania territorial da Venezuela.

Em matéria de recursos naturais, o petróleo venezuelano representa sua principal fonte de renda e sua principal ferramenta geopolítica, com a qual impulsionou sua liderança na região e sua projeção como potência energética mundial. A Venezuela possui as mais altas reservas do continente, com mais de $8.5 \mathrm{mmb}$, ocupando o $6^{\circ}$ lugar em âmbito mundial. No entanto, uma de suas principais debilidades é a ausência de uma indústria nacional de refino e petroquímica, capaz de processar suas reservas, o que gera uma forte e paradoxal dependência com respeito a países como os Estados Unidos, que ainda representam seu principal comprador $e$ provedor de gasolina e derivados.

O projeto da Petroamérica representa a principal iniciativa de integração energética na América Latina, e a mais extensiva ferramenta geopolítica na qual a Venezuela se apoia para obter uma liderança sólida na região. Dessa forma, a ajuda financeira através da petropolítica alcançou níveis recordes, sendo maior que a distinada pelos Estados Unidos a vários países como os do Caribe, onde o projeto da Petrocaribe alcançou maior institucionalização e efetividade.

No âmbito internacional, destaca-se o papel central de Hugo Chávez na Organização de Países Produtores de Petróleo (OPEP). A partir da Cúpula da organização, realizada em Caracas, no ano 2000, depois de ir a dez países árabes membros incluindo Iraque, Irã e Líbia -, a Venezuela impulsionou a reativação do grupo petroleiro, sugerindo a necessidade de conceder-lhe um novo perfil político e o fortalecimento dos preços do petróleo como ferramenta geopolítica de resistência às ameaças que os Estados Unidos representam para vários países membros, em especial o Irã. A esse in- tenso ativismo energético se agregam sua participação como promotor do projeto de uma OPEP do Gás, que teria o apoio do Irã, Catar e Argélia, além da Rússia, e na qual a Venezuela funcionaria como dobradiça entre a Bolívia e os países com principais reservas de gás no mundo (Jalife, 2007).

Junto a essa exposição de diplomacia petroleira, o projeto ideológico de Chávez procura ressonância não somente através da iniciativa regional da ALBA, como modelo de integração latinoamericana, mas também com o projeto do Socialismo do Século XXI, que visa a influenciar e liderar o debate sobre novas orientações do socialismo de Estado do século XX, e do socialismo de mercado, representado pela China e pelo Vietnã. É um projeto que visa a definir a si mesmo como modelo alternativo de organização social, política e econômica para o status quo dos processos de centro do sistema mundo, ao limitar a estrutura de exploração tradicional do capitalismo (Houtart, 2007), fortalecido também, pela conjuntura de integração regional latino-americana e pela legitimidade política do seu regime político nacional.

Diante desse ascendente protagonismo da Venezuela, e a aparente disputa com o Brasil pela liderança no Cone Sul e nos processos de integração em andamento, Rafael Calduch (2007) considera que, apesar da massa crítica em termos geopolíticos que possui a Venezuela, e um perfil particular como potência energética, ela não possui a capacidade de gestão global que tem o Brasil, reconhecido como o interlocutor válido para os assuntos de segurança política e econômica da América Latina pelas potências centrais do sistema mundo. No entanto, apesar desses limites e dos contínuos paradoxos do discurso chavista, a Venezuela possui uma projeção geopolítica que a converte em um país que projeta um status de semiperiferia anti-hegemônica, de grande relevância na consolidação dos projetos de integração latino-americana. 


\section{ATORES TRANSNACIONAIS DASOCIEDADE CIVIL LATINO-AMERICANA E SEUS ESPAÇOS DE REPRESENTAÇÃO CONTRA-HEGEMÔNICA NO SISTEMA-MUNDO}

A emergência da semiperiferia latino-americana, exposta anteriormente, produz um realinhamento e novas projeções geopolíticas do mapa de alianças e rivalidades entre os Estados nacionais e blocos emergentes que gravitam na dinâmica do sistema-mundo. Porém eles não estão isentos da influência de novos atores sociais nacionais e supranacionais de caráter antineoliberal, cujas resistências podem chegar a condicionar ou impulsionar, com maior ímpeto, essas projeções e realinhamentos, dado que esses atores - cuja força não se restringe ao novo mapa de governos nacionais de esquerda - são geradores de espaços de representação contra-hegemônicos, anti-sistêmicos ou alternativos ao imaginário social dominante no sistema-mundo.

Esses espaços de representação são entendidos como o conjunto de espacialidades utópicas desafiantes às definições e práticas espaciais dominantes, geradas pela sociedade civil desde sua experiência diária de inconformidade e novas necessidades (Lefebvre, 1974). No entanto, a conformação de foros, redes e projetos de resistência transnacionais, na última década, foi capaz de gerar sua própria projeção territorial, um contra-espaço que se opõe às representações espaciais dominantes no sistema-mundo, e tenta desconstruílas, seja mediante a exposição de sua "artificialidade (o que as leva à invalidação e o potencial fracasso), ou revertendo à representação e apropriando-se dela. (Cairo, 2007).

No primeiro caso, é possível identificar as ações convocadas pela organização civil Aliança Social Continental (ASC), que teve como premissa central a oposição ao livre comércio ortodoxo da América Latina, impulsionando a Campanha Continental de Luta Contra a ALCA, em 2002, contra o TLCAN desde 1994 e o conjunto de TLCs bilaterais, assinados entre Estados Unidos e os Estados latino-americanos. De forma paralela, as
Cúpulas dos Povos de América assumiram crescente importância, pois organizaram distintos contraforos às Cúpulas presidenciais das Américas, e conformaram redes permanentes de resistência e projetos contra-espaciais, dedicados a expor a artificialidade da ALCA e o livre comércio. A III Cúpula dos Povos, em Mar del Plata (Argentina), em 2005, conformou parte da cojuntura do colapso da ALCA em seu formato original, e continua seu processo contra o novo formato ALCA em fragmentos. Sua proposta conseguiu ter uma conexão de apoio significativo à ALBA, interpretada como espaço alternativo de integração latinoamericana.

Quanto à segunda estratégia, orientada para ressignificar as representações dominantes, apropriando-se delas, é possível identificar vários projetos que se destacam na América Latina. O primeiro é, por excelência, o espaço contemporâneo que aglutina uma imensa variedade de formas de resistência política, econômica, social, cultural e ambiental, antineoliberal: o Foro Social Mundial (FSM).

OFSM não foi somente o contraforo representativo das demandas e dos atores ausentes no Foro Econômico Mundial (FEM) de Davos (Suiça), mas chegou a constituir-se num espaço global aberto, para o encontro de movimientos, organizações e lutas diversas, expressas numa babélica variedade de idiomas, filosofias e formas de conhecimento ocidentais e não ocidentais, que defendem concepções da dignidade humana e a utopia para a transformação do mundo. Daí que autores como Boaventura de Souza Santos (2007) encontrem uma relativa debilidade desse contra-espaço mundial, que carece de resposta "à questão do por quê, para quê, em que condições e em benefício de quem dita diversidade," (Souza, 2008, p. 45), ou seja, uma consigna homogênea, utilizada pelos projetos tradicionais de esquerda.

Mas justamente essa debilidade se acompanha do "acerto de fazer esta diversidade mais visível e mais aceitável para os movimentos e as organizações [fazendo-as] conscientes do caráter incompleto ou parcial de suas lutas, políticas e filosofias" (2008, p. 46). Como plataforma dessa diversi- 
dade incompleta e aglutinadora de diferentes formas e práticas de utopia, o FSM representa uma matriz muito significativa na resistência da esquerda global às projeções geopolíticas dos processos de centro e, inclusive, das alianças e blocos SulSul, que não são alheias às diversas demandas de suas sociedades.

Um segundo projeto que acompanha a estratégia de ressignificação, é a iniciativa empreendida por diversos grupos da sociedade civil dos países membros do Mercosul, orientada para a consolidação do Mercosul dos povos, como um foro de reunião mais efetivo que o desenvolvido pelas chancelarias. Esse trabalho levou à formação do Programa Mercosul Social e Solidário, concentrado em impulsionar uma cidadania regional ativa, mediante a incorporação de uma carta social com maior alcance no órgão de integração oficial.

O terceiro é a iniciativa proposta pelo presidente Evo Morales, no marco da cúpula dos povos, e a ALBA, o Tratado de Comércio entre os Povos (TCP), representando não somente a alternativa oposta aos TLCs e aos Acordos de Cooperação Econômica (ACE) promovidos pelo modelo econômico liberal vigente como opção única de comércio entre as nações. No entanto, os TCP excedem uma mera oposição, ao entender o "comércio e a inversão como fins em si mesmos, mas como meios do desenvolvimento, por isso seu objetivo não é a liberalização absoluta dos mercados e a 'redução' dos Estados, mas o benefício para os povos" (CENDA, 2006).

Outro exemplo de contra-espacialidade mais contundente é representado pela iniciativa dos caracóis zapatistas, no estado de Chiapas, México. Esse projeto se opõe ao funcionamento político, administrativo e territorial que programa o sistema político mexicano como forma de organização homogênea e dominante. A autonomia, como consigna de organização, e o trabalho político denunciam a artificialidade do sistema político mexicano com respeito aos povos indígenas e às demandas de diversos grupos sociais anti-neoliberais. Esse projeto de organização local alcançou sua projeção nacional a partir do Plano A Realidade-
Tijuana - REALITI, em 2003, que exortava à promoção e à defesa "das formas de autogestão e autogoverno em todo o território nacional, de acordo com os modos de cada um" (EZLN, 2008). Dessa forma, o imaginário zapatista, dentro de sua projeção universal com respeito à dignidade humana, à resistência, à autoorganização dos povos e à transformação do mundo sem tomar o poder, simbolizou um importante limite à projeção geopolítica do Estado mexicano, a partir do PPP+C, TLCAN e ASPAN.

Outra das manifestações específicas dos atores sociais na América Latina foi a representada pelo movimento indígena da Bolívia, que, após a gestação de uma crescente mobilidade política de base, concretizou, em 2006, a sua incorporaçao à estrutura de poder estatal por meio de um processo democrático ativo. O movimento indígena boliviano transitou de um movimento social antiestatal e anti-sistêmico para converter-se na base do partido Movimento ao Socialismo (MAS) e, como conseqüência, do governo central. Dessa forma, constitui um movimento social que se apoderava como tomador de decisões mediante os processos tradicionais do Estado moderno, mas fundado nos projetos de base, transformando as demandas da Cúpula dos Povos e iniciativas como os TCPs e as autonomias indígenas em políticas de Estado. Daí que represente a aposta pelo compromisso com a transformação e o cumprimento das demandas das bases sociais.

O que se destaca, nessas diferentes manifestações de resistência, é a identificação de três grandes tendências que as projeções geopolíticas dos países semiperiféricos da região enfrentam, e as alianças e blocos supranacionais Norte-Sul e Sul-Sul. A primeira é a que se opõe radicalmente a qualquer forma de poder imposto de maneira vertical pelos atores instituídos do sistema-mundo, procurando uma contra-representação, desde o apossar-se das bases autoorganizadas, tal e como o movimento zapatista e alguns movimentos indígenas andinos, que procuram, além disso, uma projeção continental.

A segunda é uma perspectiva de reforma 
que procura conciliar as agendas dos movimentos sociais e o ativismo cidadão com as agendas dos Estados e blocos supranacionais, tais como o Mercosul dos Povos ou UNASUL. Finalmente, a terceira tendência manifesta uma colaboração e um compromisso dos movimentos sociais com o Estado e as iniciativas regionais, fortalecendo os projetos e alianças Sul-Sul, como ocorre no caso do movimento indígena boliviano e do movimento bolivariano da Venezuela, com relação ao projeto de Estado e à ALBA.

(Tradução de Consuelo Brito de Freitas)

(Recebido para publicação em julho de 2008) (Aceito em agosto de 2008)

\section{REFERÊNCIAS}

BALANCE de política estratégica de defensa y asuntos exteriores. Sistema de Información Global, [S.l.] 2006/ 2007.

BALLESTER, Horacio. La adaptación al siglo XXI de la vieja doctrina de la seguridad nacional. Agencia Latinoamericana de Información. 2008. Disponible em: www.alainet.org/active/24020.

BUZAN, Barry et al. Regions and powers. The structure of international security. Cambridge: Cambridge University Press, 2003.

CAIRO, Heriberto. La definición de mesoamérica. In: PRECIADO, Jaime; ROCHA, Alberto (Ed.) La $\overline{c o n s t r u c c i o ́ n ~ d e ~ u n a ~ r e g i o ́ n . ~ M e ́ x i c o ~ y ~ l a ~ g e o p o l i ́ t i c a ~ d e l ~}$ Plan Puebla Panamá, UCM/Catarata.Madrid: UCM, 2007.

CALDUCH, Rafael. Venezuela no puede competir con el liderazgo que ejerce Brasil. Entrevista concedida en el Diario Clarín, Buenos Aires, 9 abr. 2008.

CECEÑA, Ana Esther. La base de Manta. Posición neurálgica de Estados Unidos en la región andino-amazónica. Observatorio Latinoamericano de Geopolítica. Disponible em: www.geopolitica.ws/leer.php/12. Acesso em 2008.

CENDA. Centro de Comunicación y Desarrollo Andino. $T C P$ : la propuesta boliviana para un comercio justo entre los pueblos. Cochabamba-Bo, 2006. Disponible em: www.constituyentesoberana. org/info/?q=node/316. Acesso em: maio 2008.

EZLN-CCRI-CG, Plan realidad-Tijuana. Disponible em: www.nodo50.org/ pchiapas/chiapas/documentos/caracol/ caracol9.htm. Acesso em: abr., 2008.

HERNÁNDEZ B., Loyola. Petroamérica y la integración energética de América Latina y el Caribe. Caracas: Instituto de Altos Estudios Diplomáticos Pedro Gual, 2007.

HOUTART, François. Socialismo del siglo XXI, construcción intelectual, eslogan político o expresión de las luchas antisistémicas. In: SEMINARIO EN MEMORIA DE ANDRES AUBRY. Tuxtela Gutiérrez-Mx: Universidad de la Tierra de San Cristóbal de Las Casas, 2007.
JALIFE, Alfredo. Nueva OPEP del gas contra EU y la UE, Diario La Jornada, [S.l.], 25 mar. 2007.

JONES, Richard; HILDRETH, S. A. (Ed.). Emerging powers: defense and security in the third world. Nueva York: Preager, 1986.

LEFEVRE, Henry. La production de l'espace. París: Anthropos, 1974.

MERLE, Marcel. Sociología de las relaciones internacionales. Madrid: Alianza, 1976.

MPPRE. Ministerio de Poder Popular para las Relaciones Exteriores. Fundamentos filosóficos de la nueva integración del Sur. Caracas: Instituto de Altos Estudios Diplomáticos Pedro Gual, 2007.

NOLTE, Detlef. How to compare regional powers: analytical concepts and research topics. Germany: German Institute of Global and Area Studies, 2007.

NYE, Joseph. The challenge of soft power. Time, Washington, Disponible en: www.time.com/time/magazine/article/ 0,9171,21163,00.html, Acceso en 22 feb., 1999.

PRATT, C. (ed.) Middle power internationalism: the NorthSouth dimension. Kingston-Montreal: McGill-Queens University Press, 1990.

PRECIADO, Jaime. La alianza para la seguridad y la prosperidad de norteamérica: baja institucionalización sin contrapesos ni agenda social. Revista Configuraciones, Jálisco-Mx: Universidad de Guadalajara n. 1, ene./jun., 2008.

PNUD. Programa de las Naciones Unidas para el Desarrollo Reporte sobre de Desarrollo Humano, 2007/2008. Manágua, Nicarágua: 2007/2008.

RAMOS, Pablo. Sin símbolos ni platillos nació la UNASUR. Agencia Latinoamericana de Información, 2006. Disponible em www.alainet.org/active/24265. Acceso en mayo, 2008.

SOUZA SANTOS, Boaventura. El Foro Social Mundial y la Izquierda Global. El Viejo Topo, Madrid, Universidad Complutense Marid, n. 240, 2008.

TAYLOR, Peter; FLINT Colin. Geografía política. Economíamundo, Estado-nación y localidad. Madrid: Trama Editorial, 2002. 


\section{LATIN AMERICA IN THE WORLD SYSTEM: questions and alliances between periphery and center}

\section{Jaime Preciado}

The economical and political matrix in Latin America and the Caribbean is divided internally by the emergency of supranational blocks that demand a new geopolitical projection, through negotiations between spaces and scopes of power between center and periphery. From this perspective, strategies are implemented that influence the new configuration of the world system. In this paper, we try to identify the national States with the ability to project themselves as an active semi-periphery. Mexico has for her objective to reinforce the strategy of North America and appears as a subordinate semiperiphery. Brazil project herself as a semiperiphery with aspirations of global South-North potency, questioning and redefining her relations with the world central powers. The emergency of a anti-hegemonic semiperiphery is commanded by Venezuela, through an active international South-South policy. Simultaneously, new alternative world actors emerge that are not limited to the map of national governments of "left" but carry an alternative social and anti-hegemonic imaginary of the World system.

KEYwords: geopolitics, international relations, Latin America and Caribbean, World system, alternative world actors.

\section{L'AMÉRIQUE LATINE DANS LESYSTÈME-MONDE: les questions et les alliances centre - périphérie}

\author{
Jaime Preciado
}

La matrice économique et politique latinoaméricaine et caribéenne a été divisée à l'intérieur d'ellemême par le surgissement de blocs supranationaux qui demandent une nouvelle projection géopolitique face aux négociations entre des espaces et des domaines du pouvoir central et périphérique. C'est à partir de ce moment là que des stratégies capables d'influencer la nouvelle configuration du système-monde sont mises en place. Dans cet article, on identifie les Etats-Nations comme capables de se projeter comme une semipériphérie active. Le Mexique a comme objectif de renforcer la stratégie de l'Amérique du Nord et occupe la place d'une semi-périphérie soumise. Le Brésil se projette comme une semi-périphérie, aux aspirations de puissance globale Sud-Nord, qui remet en question et redéfinit ses relations avec les pouvoirs centraux mondiaux. Le surgissement d'une semi-périphérie antihégémonique est dirigé par le Venezuela grâce à une politique internationale active Sud-Sud. Simultanément, de nouveaux acteurs alter mondialistes surgissent qui ne se limitent pas au plan des gouvernements nationaux de "gauche", mais ont un imaginaire social alternatif et anti-hégémonique du Système-Monde.

Mотs-CLÉs : géopolitique, relations internationales, Amérique Latine et Caraïbe, système-monde, acteurs alter mondialistes. 